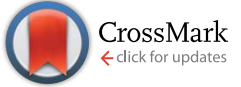

Cite this: RSC Adv., 2017, 7, 1200

Received 21st November 2016 Accepted 15th December 2016

DOI: $10.1039 / c 6 r a 27072 g$

www.rsc.org/advances

\section{Efficient conversion of wheat straw into furan compounds, bio-oils, and phosphate fertilizers by a combination of hydrolysis and catalytic pyrolysis $\uparrow$}

\begin{abstract}
Haian Xia, * Siquan Xu and Li Yang*
The development of sustainable techniques to convert lignocellulosic materials into value-added chemicals remains a significant challenge. Herein, we report a novel technique to directly convert wheat straw to furan compounds, bio-oils, and phosphate fertilizers. Untreated wheat straw was initially converted into 5hydroxymethylfurfural (HMF) and furfural in a biphasic reaction system using $\mathrm{FePO}_{4}$ and $\mathrm{NaH}_{2} \mathrm{PO}_{4}$ as cocatalyst. The remaining $\mathrm{FePO}_{4}$ in the solid residues was used as the catalyst to pyrolyze the solid residues, producing bio-oils and bio-char-based phosphate fertilizers. This combination of $\mathrm{FePO}_{4}$ and $\mathrm{NaH}_{2} \mathrm{PO}_{4}$ co-catalyst exhibited higher selectivity towards HMF and furfural production than using only $\mathrm{FePO}_{4}$ as a catalyst in the conversion of wheat straw. The maximum HMF yield, $44 \%$, was obtained when the reaction was carried out at $160{ }^{\circ} \mathrm{C}$ for $60 \mathrm{~min}$, while the highest furfural yield, $92 \%$, was achieved when the reaction occurred at $150{ }^{\circ} \mathrm{C}$ for $60 \mathrm{~min}$. This reaction system is one of the most effective reaction systems to date for the conversion of wheat straw. Excessive Brønsted or Lewis acid sites (Fe ions) cannot give high yields of HMF and furfural due to the formation of by-products, indicating that a synergistic combination of Brønsted and Lewis acid sites is critical to obtain high yields of furan compounds. Interestingly, $\mathrm{FePO}_{4}$ could effectively catalyze the pyrolysis of unconverted cellulose into new compounds, such as 5-methylfuran and 2,5-methylfuran, which is not observed in non-catalyzed pyrolysis.
\end{abstract}

\section{Introduction}

Lignocellulosic biomass in agricultural and forestry residues is the only sufficiently common and sustainable resource for conversion to renewable bio-fuels and bio-chemicals. ${ }^{1-8}$ Using lignocellulosic biomass as a renewable energy source offers a unique opportunity for a sustainable society, with an unprecedented influence on the economy as well as energy security and independence. ${ }^{\mathbf{1 , 2}, 9}$ Lignocellulosic material such as straws (wheat, corn, rice, etc.), have great industrial potential because they are available in large quantities worldwide and are cheap and renewable..$^{10-12}$ Wheat straw is one of the major agricultural residues in terms of its availability and low cost. ${ }^{\mathbf{1 1 2}}$ China produces approximately 100 million tons (Mt) of wheat straw (as a by-product) annually. ${ }^{13,14}$ Thus, there is a pressing need to develop effective strategies for the total utilization of lignocellulosic materials to produce valuable chemicals or drop-in fuels.

Wheat straw is composed of three main polymers, cellulose, hemicellulose, and lignin. ${ }^{\mathbf{1 1 2}, \mathbf{1 4}}$ To efficiently convert these

Jiangsu Key Lab of Biomass-Based Green Fuels and Chemicals, College of Chemical Engineering, Nanjing Forestry University, Nanjing 210037, China. E-mail: haxia@ dicp.ac.cn; yangli157@163.com; Fax: +86-25-85428873; Tel: +86-25-85427635

$\uparrow$ Electronic supplementary information (ESI) available. See DOI: 10.1039/c6ra27072g lignocellulosic materials into bio-fuels or chemicals, pretreatment techniques are usually required due to the heterogeneous and recalcitrant nature of lignocellulose. Recently, substantial research efforts have focused on initially separating lignocellulosic materials into hemicelluloses, cellulose and lignin prior to converting them. ${ }^{15,16}$ However, pretreatment techniques increase the price of bio-fuels or downstream products. Additionally, currently reported strategies have been predominately optimized for oxygenated fuels derived from cellulose such as ethanol. ${ }^{17}$ Unfortunately, minor components are usually neglected, decreasing the industrial viability of processing lignocellulosic materials. Consequently, lignocellulosic biofuels and bio-based chemicals are more expensive than petroleumderived fuels or chemicals. ${ }^{1,9}$ To obtain maximal carbon yields and permit cost-effective operation, biorefineries must offer an economical conversion pathway of hemicelluloses and lignin to value-added chemicals. Given the unique physical and chemical properties of lignocellulosic materials, a cost-effective lignocelluloses-to-fuels process will likely demand a multifaceted approach (e.g., the combination of hydrolysis and pyrolysis) by which each biomass component is utilized economically to maximize carbon yields to desired products.

The combination of hydrolysis and catalytic pyrolysis is an excellent pathway to transform lignocellulosic materials into valuable chemicals. If hydrolysis is used as the initial step, 
hemicelluloses and cellulose may be hydrolyzed to mono- and oligo-saccharides, followed by a dehydration step at which these sugars are converted to furfural and HMF. ${ }^{1,2} \mathrm{HMF}$ and furfural are important platform chemicals for the production of fine chemicals, plastics, pharmaceuticals, and liquid fuel. ${ }^{18-29}$ For example, HMF can be converted into the gasoline additives 2,5dimethylfuran (DMF), ${ }^{30,31}$ an alternative polymer precursor of 2,5-furandicarboxylic acid (FDCA), ${ }^{7,18,32}$ and levulinic acid, ${ }^{25,33}$ etc. However, such a "one-pot" synthesis of furfural and HMF from lignocellulosic materials with high efficiency in aqueous media without adding mineral acids remains a tremendous challenge because the inedible biomass is relatively recalcitrant and heterogeneous, making its conversion uneconomical or environmentally unfriendly. ${ }^{27,29}$ Solid residues containing mostly lignin are obtained after the hydrolysis of lignocellulose materials. Catalytic pyrolysis may be an efficient method to convert lignin into bio-oils composed of aromatics and biochar. $^{34,35}$

To that end, we have developed a novel strategy to convert wheat straw into 5-HMF, furfural, bio-oils, and bio-char-based phosphate fertilizers by combining carbohydrate hydrolysis with the pyrolysis of its hydrolyzed solid residues. The objective of this study is to explore the transformation of non-food biomass to furan compounds, bio-oils and bio-char-based phosphate fertilizers with maximum economic efficiency, and this strategy is summarized in Fig. 1. We first prepared furfural and HMF from wheat straw using $\mathrm{FePO}_{4}$ and $\mathrm{NaH}_{2} \mathrm{PO}_{4}$ as cocatalyst. After the hydrolysis reaction, the solid residues that remained were pyrolyzed to produce bio-oils and bio-char-based phosphate fertilizers. The role of $\mathrm{FePO}_{4}$ and $\mathrm{NaH}_{2} \mathrm{PO}_{4}$ as cocatalyst in the conversion of wheat straw to furfural and HMF was studied. In addition, one significant advantage of this strategy is that $\mathrm{FePO}_{4}$ can be used as the catalyst to hydrolyze holocelluloses, as a catalyst for the pyrolysis of the solid residue and as a component in phosphate fertilizer.

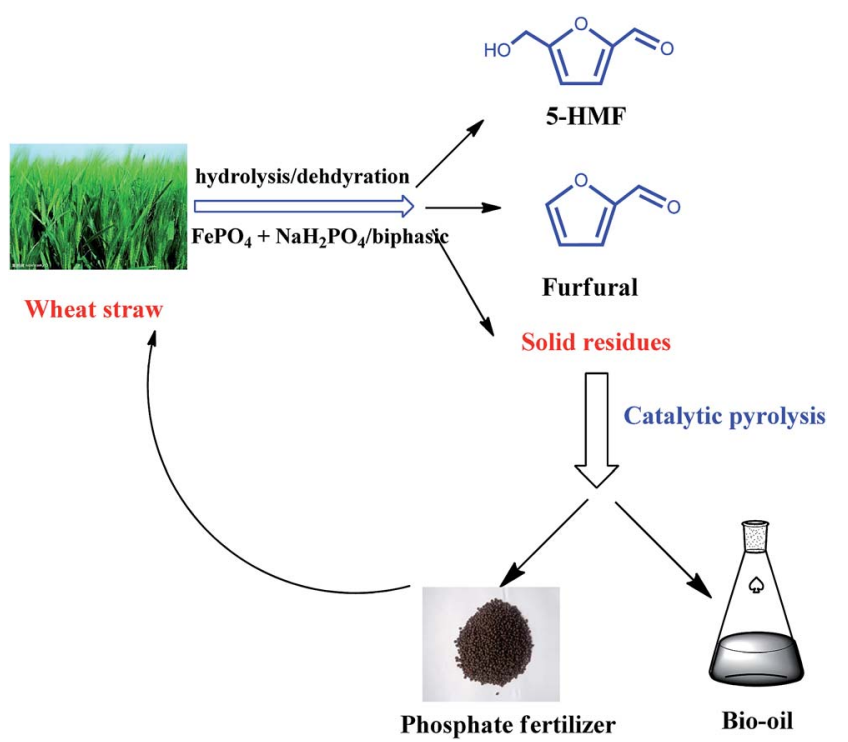

Fig. 1 The conversion pathway of wheat straw.

\section{Experimental}

\subsection{Materials}

Wheat straw was collected from Hebei province, China. The straw was analyzed according to the analytical methods of the National Renewable Energy Laboratory (NREL), and the content of ash, hemi-cellulose, cellulose, and lignin was 9.8\%, 25.6\%, 35.5\%, and $20.1 \%$, respectively. ${ }^{36}$ The material was ground to a size smaller than 400 mesh and hydrolyzed directly without additional pretreatment. The catalyst, $\mathrm{FePO}_{4} \cdot 2 \mathrm{H}_{2} \mathrm{O}$ was purchased from Sigma-Aldrich. Other materials $\left(\mathrm{NaH}_{2} \mathrm{PO}_{4}, \mathrm{NaCl}\right.$, 1-butanol, 2-butanol, toluene, methyl isobutyl ketone (MIBK) and tetrahydrofuran) were purchased from Aladdin Co. Ltd. in China.

Conversion of wheat straw was carried out in a $100 \mathrm{~mL}$ stainless steel autoclave heated in a temperature-controlled furnace. The catalysts and the feedstock were placed into the autoclave, which contained the organic solvent/distilled water mixture. The reaction was conducted under nitrogen (typically 5 bar at room temperature) and heated to the appropriate temperature. The reactions were stopped by cooling the reactor in an ice bath, and the products were separated into three portions: an aqueous phase, an organic phase, and a solid residue. The liquid and solid fractions were collected by repeatedly washing the inside of the reactor with distilled water. The solid residues were dried at $120{ }^{\circ} \mathrm{C}$ overnight and weighed to determine their mass. The solid residue was mainly composed of unreacted feedstock, $\mathrm{FePO}_{4}$ catalyst and side products such as humins.

Sample analyses were performed using high-performance liquid chromatography (an Agilent 1200 system equipped with an UV detector set at $280 \mathrm{~nm}$ ). $\mathrm{HMF}$ and furfural concentrations were monitored with a Zorbax SB-C18 column using a water-methanol $(30: 70, \mathrm{v} / \mathrm{v})$ solution as the mobile phase, a flow rate of $0.5 \mathrm{~mL}$ $\min ^{-1}$ and a column temperature of $30{ }^{\circ} \mathrm{C}$. The yield of $\mathrm{HMF} /$ furfural was calculated as: yield $(\%)=$ (moles of $\mathrm{HMF} /$ furfural in the products $) /($ moles of glucan/xylan put into the reactor $) \times 100$.

IR spectra of fresh $\mathrm{FePO}_{4} \cdot 2 \mathrm{H}_{2} \mathrm{O}$ and the used catalyst were recorded on a Thermo Nicolet Nexus 470 spectrometer. The Fe content of the aqueous phases collected from the conversion of cellulose was measured by atomic absorption spectroscopy (AAS). XRD patterns were recorded on a Rigaku Ultima IV X-ray diffractometer equipped with a $\mathrm{Cu} \mathrm{K} \alpha \mathrm{X}$-ray source operating at $40 \mathrm{kV}$ and $30 \mathrm{~mA}$.

Pyrolysis studies were conducted using a commercial pyrolyzer (PY-3030D, Frontier Lab, Japan) coupled with a GC-MS system (6890N gas chromatograph with an HP-5 column combined with a 5973 mass selective single quadrupole mass spectrometer from Agilent Technologies, USA). Approximately $20 \mathrm{mg}$ of a sample (solid residues or wheat straw) was pyrolyzed by inserting the sample between quartz wool in a quartz tube and heating the samples to $600{ }^{\circ} \mathrm{C}$ with a filament ramping rate of $1000{ }^{\circ} \mathrm{C} \mathrm{s}^{-1}$.

\section{Results and discussion}

\subsection{The conversion of wheat straw using $\mathrm{FePO}_{4}$ and $\mathrm{NaH}_{2} \mathrm{PO}_{4}$ as co-catalyst}

To evaluate the catalytic performance of using only $\mathrm{FePO}_{4}$ as the catalyst, the impact of varying several different reaction 
conditions, such as reaction temperature, reaction time, and catalyst amount, was investigated (Table $1 \mathrm{~S}$ and Fig. 1S, ESI $\dagger$ ). The highest furfural yield, $71 \%$, was obtained when $0.5 \mathrm{~g}$ of the $\mathrm{FePO}_{4}$ catalyst was used.

To further improve the $\mathrm{HMF}$ and furfural yields, $\mathrm{NaH}_{2} \mathrm{PO}_{4}$ was added as a co-catalyst (Table 1 ). Combining minor amounts of $\mathrm{NaH}_{2} \mathrm{PO}_{4}$ with $\mathrm{FePO}_{4}$ substantially increased the HMF and furfural yields compared to using only $\mathrm{FePO}_{4}$ or $\mathrm{NaH}_{2} \mathrm{PO}_{4}$ as the catalyst (Table 1 , entries 1,2 , and 4 ). In addition, this combination of catalysts caused a remarkable reduction in the mass of solid residues compared to those produced by using only $\mathrm{FePO}_{4}$ as the catalyst (entry 1 vs. 4, Table 1). However, increasing the amount of $\mathrm{NaH}_{2} \mathrm{PO}_{4}$ resulted in a drop in the yield of HMF from $36 \%$ to $26 \%$ for $0.02 \mathrm{~g}$ and $0.05 \mathrm{~g}$ of $\mathrm{NaH}_{2} \mathrm{PO}_{4}$, respectively. This result implies that excessive Brønsted acid sites are unfavorable for HMF formation (Table 1, entries 5, 10, and 11). In contrast, the furfural yields first increased and then decreased as more $\mathrm{NaH}_{2} \mathrm{PO}_{4}$ was added (Table 1, entries 5, 10, and 11) and suggested that the influence of the acidic salt dosage on the yields of HMF and furfural differs under the same conditions.

The effect of reaction temperature and $\mathrm{FePO}_{4}$ dosage on the yields of HMF and furfural was also investigated, as shown in Table 1. An HMF yield of up to $44 \%$ and a high furfural yield of $88 \%$ were achieved at $170{ }^{\circ} \mathrm{C}$ for $60 \mathrm{~min}$. However, the highest furfural yield, $92 \%$, was obtained when the reaction occurred at $150{ }^{\circ} \mathrm{C}$ for $60 \mathrm{~min}$. It seems that a high yield of furfural is easier to achieve than a high yield of HMF. Raines et al. reported a high HMF yield, 48\%, which was obtained from corn stover using a complex ionic liquor and DMA-LiCl systems in the presence of $\mathrm{CrCl}_{3}$ and $\mathrm{HCl}^{37}$ Wyman et al. coupled $\mathrm{FeCl}_{3}$ and $\mathrm{H}_{2} \mathrm{SO}_{4}$ to catalyze the degradation of maple wood to obtain the highest HMF yield, 51\%, and the yield of furfural up to $97 \% .^{38}$ Mazza et al. investigated $\mathrm{HCl}$ acid-catalyzed conversion of wheat straw by a microwave assisted reaction, and obtained the yield of HMF and furfural up to $66 \%$ and $3.4 \%$, respectively. ${ }^{11}$ Therefore, this reaction system can be regarded as one of the most effective reaction systems to date for the conversion of lignocellulosic feedstocks.
It is generally accepted the generation of $\mathrm{HMF} /$ furfural from lignocellulosic feedstocks must include acid catalyzed depolymerization of cellulose/hemicellulose to produce glucose/xylose in the first step..$^{39,40}$ Subsequently, isomerization of glucose/ xylose to fructose/xylulose takes place followed by its subsequent dehydration to $\mathrm{HMF} /$ furfural. It is well known that the cracking of 1,4-glucosidic bonds of cellulose/hemicellulose is catalyzed by protonic acid $\mathrm{H}^{+}{ }^{29}$ In this work, $\mathrm{FePO}_{4}$ can be hydrolyzed into the hydroxylated $\mathrm{Fe}$ species and $\mathrm{H}^{+}$, or acidic salts is able to supply $\mathrm{H}^{+}{ }^{29}$ The hydroxylated Fe species acts as Lewis acid sites catalyzing the isomerization of glucose/xylose into fructose/xylulose. It seems likely that synergistic catalysis is critical for the production of HMF and furfural. In other words, excessive Lewis or Brønsted acid sites inhibit high HMF and/or furfural yields. This suggests that a good match is required for three reactions that occur, the depolymerization of cellulose/xylan to glucose/xylose, the isomerization of glucose into fructose/xylulose, and the dehydration of fructose/xylulose into HMF/furfural, in order to obtain high HMF and furfural yields.

We also investigated the impact of different organic solvents on the HMF and furfural yields. As shown in Fig. 2, the usage of $\mathrm{H}_{2} \mathrm{O} / \mathrm{THF}$ resulted in higher $\mathrm{HMF}$ and furfural yields with a concomitant reduction in the solid residue mass. Additionally, these solvents have various partition coefficients towards furfural and $\mathrm{HMF}$; for example, a bi-phasic 2-butanol $/ \mathrm{H}_{2} \mathrm{O}$ system produced a comparable furfural yield but generated a lower $\mathrm{HMF}$ yield compared to $\mathrm{MIBK} / \mathrm{H}_{2} \mathrm{O}$.

To study the influence of other acidic salts on the HMF and furfural yields, various co-catalysts, such as $\mathrm{NaHSO}_{4}$ and $\mathrm{NaHSO}_{3}$, were used to catalyze the conversion of wheat straw. As shown in Table 2, when an equal molar amount $(0.02 \mathrm{~g})$ of $\mathrm{NaHSO}_{4}$ was used as the co-catalyst, the yields of HMF and furfural were $33 \%$ and $74 \%$, respectively; however, both of these yields were lower than when $\mathrm{NaH}_{2} \mathrm{PO}_{4}$ was used as the cocatalyst (Table 2, entry 1 vs. 3). Decreasing the amount of $\mathrm{NaHSO}_{4}$ also decreased the furfural and HMF yields (Table 2, entry 2 vs. 3). Using $\mathrm{NaHSO}_{3}$ increased both the furfural yield (84\%) and the HMF yield (37\%) compared to $\mathrm{NaHSO}_{4}$, but these

Table 1 Results for the conversion of wheat straw into HMF and furfural using $\mathrm{FePO}_{4}$ and $\mathrm{NaH}_{2} \mathrm{PO}_{4}$ as the co-catalyst ${ }^{a}$

\begin{tabular}{|c|c|c|c|c|c|c|c|}
\hline Entry & Tem. $/{ }^{\circ} \mathrm{C}$ & Time/min & $\mathrm{FePO}_{4} / \mathrm{g}$ & $\mathrm{NaH}_{2} \mathrm{PO}_{4} / \mathrm{g}$ & HMF yield $/ \%$ & Furfural yield ${ }^{c} / \%$ & Solid residues ${ }^{d} / \mathrm{g}$ \\
\hline 1 & 160 & 60 & 0.20 & 0 & 22 & 60 & 0.603 \\
\hline 2 & 160 & 60 & 0 & 0.02 & 19 & 54 & 0.490 \\
\hline 4 & 160 & 60 & 0.20 & 0.02 & 44 & 88 & 0.459 \\
\hline 5 & 170 & 60 & 0.20 & 0.02 & 36 & 74 & 0.420 \\
\hline 6 & 160 & 60 & 0.10 & 0.02 & 26 & 60 & 0.523 \\
\hline 9 & 160 & 90 & 0.20 & 0.02 & 37 & 77 & 0.451 \\
\hline 10 & 170 & 60 & 0.20 & 0.01 & 30 & 60 & 0.450 \\
\hline 11 & 170 & 60 & 0.20 & 0.05 & 26 & 76 & 0.469 \\
\hline
\end{tabular}

${ }^{a}$ Reaction conditions: $1.0 \mathrm{~g}$ wheat straw, $10.0 \mathrm{~mL}$ deionized water, $30.0 \mathrm{~mL}$ THF, $3.5 \mathrm{~g} \mathrm{NaCl} .{ }^{b} \mathrm{HMF}$ yield is calculated based on the cellulose content of wheat straw. ${ }^{c}$ Furfural yield is calculated based on the xylan content of wheat straw. ${ }^{d}$ The solid residue is mainly composed of unreacted feedstock, $\mathrm{FePO}_{4}$ catalyst and side products such as humins. 


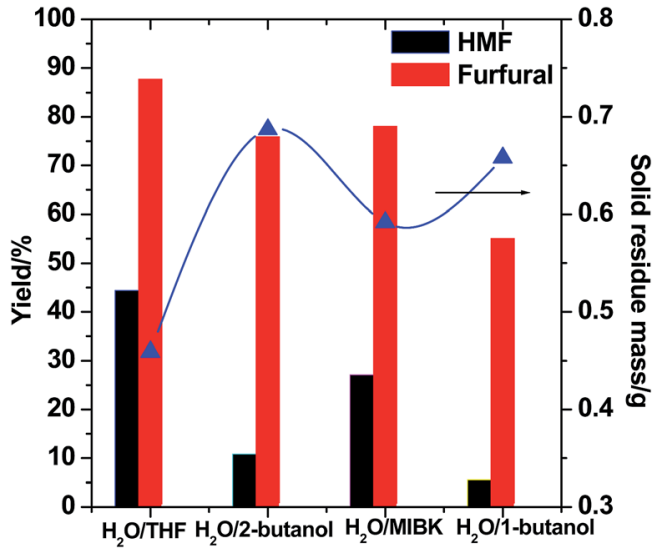

Fig. 2 The effect of organic solvent on the solid residue mass, as well as the HMF and furfural yields. Reaction conditions: $1.0 \mathrm{~g}$ wheat straw, $0.2 \mathrm{~g} \mathrm{FePO}_{4}$ catalyst, $0.02 \mathrm{~g} \mathrm{NaH}_{2} \mathrm{PO}_{4}, 10.0 \mathrm{~mL}$ deionized water, 30.0 $\mathrm{mL}$ organic solvent, $3.5 \mathrm{~g} \mathrm{NaCl}, 160{ }^{\circ} \mathrm{C}, 60 \mathrm{~min}$. The solid residue contains unreacted feedstock, $\mathrm{FePO}_{4}$ catalyst and side products such as humins

yields were still lower than when $\mathrm{NaH}_{2} \mathrm{PO}_{4}$ was used as the cocatalyst. However, all three of these co-catalysts were found to have a beneficial impact on the generation of furfural and HMF compared with using $\mathrm{FePO}_{4}$ or an acidic salt as the only catalyst (entries 1 and 2 in Table 1 vs. 2). These results further demonstrate that synergistic effects between the $\mathrm{FePO}_{4}$ and acidic salt in the production of HMF and furfural may exist.

\subsection{The nature of the solid residues}

XRD was used to investigate the nature of the solid residues. It can be seen in Fig. 3 that there are three diffraction peaks at $16.0^{\circ}, 22.5^{\circ}$, and $43.8^{\circ}$, which are assigned to incompletely converted cellulose with high crystallinity. ${ }^{\mathbf{4 1}}$ These peaks appear because the high crystallinity residues are difficult to convert, whereas the amorphous part of the cellulose is relatively easy to convert. In addition to the diffraction peaks related to microcrystalline cellulose, several new diffraction peaks were also observed. The new characteristic diffraction patterns are related to a crystalline $\mathrm{FePO}_{4} \cdot 2 \mathrm{H}_{2} \mathrm{O}$ (JCPDS no. 00-002-0250), meaning that $\mathrm{FePO}_{4} \cdot 2 \mathrm{H}_{2} \mathrm{O}$ underwent a structural transformation from an amorphous phase into a crystalline phase under hydrothermal conditions. ${ }^{29}$ The structural transformation of $\mathrm{FePO}_{4}$ also clearly showed that dissolution and recrystallization could

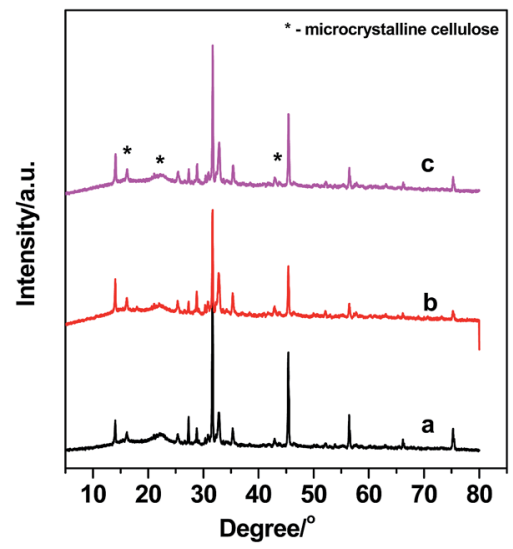

Fig. 3 XRD patterns of the solid residues obtained by the conversion of wheat straw at $160{ }^{\circ} \mathrm{C}$ for different reaction times: (a) $30 \mathrm{~min}$, (b) $60 \mathrm{~min}$, and (c) $90 \mathrm{~min}$. Reaction conditions: $1.0 \mathrm{~g}$ wheat straw, $0.2 \mathrm{~g}$ $\mathrm{FePO}_{4}$ catalyst, $0.02 \mathrm{~g} \mathrm{NaH}_{2} \mathrm{PO}_{4}, 10.0 \mathrm{~mL}$ deionized water, $30.0 \mathrm{~mL}$ THF, $3.5 \mathrm{~g} \mathrm{NaCl}$.

occur during the conversion of wheat straw. This is because $\mathrm{FePO}_{4} \cdot 2 \mathrm{H}_{2} \mathrm{O}$ is insoluble at room temperature but dissolves at the elevated temperatures achieved during the reaction process. $^{28}$

To further characterize the nature of the solid residues, IR spectroscopy was also used. As shown in Fig. 4a, several bands at $900,1001,1062,1115,1165,1255,1430,1463,1515,1654$, 1700 , and $1734 \mathrm{~cm}^{-1}$ are observed for the untreated wheat straw. The bands at 900, 1062, 1115, and $1165 \mathrm{~cm}^{-1}$ are assigned to both cellulose and hemicellulose, and the characteristic vibration at $1734 \mathrm{~cm}^{-1}$ is characteristic of an ester linkage between hemicellulose and lignin. ${ }^{42}$ Characteristic bands of lignin are observed at 1255, 1430, 1463, 1515, 1654, and $1700 \mathrm{~cm}^{-1} .^{42}$ After hydrolysis, the bands at 900 and 1734 $\mathrm{cm}^{-1}$ disappear, indicating that hemicellulose is easier to hydrolyze. As the reaction temperature increases, the characteristic bands related to cellulose are still observed, demonstrating that some microcrystalline cellulose was not converted, especially for cellulose with high crystallinity, and this is in good agreement with the XRD results (Fig. 3). As the reaction time was extended to $90 \mathrm{~min}$, the intensities of the bands related with microcrystalline cellulose decreased considerably, indicating the additional conversion of the relatively unreactive microcrystalline cellulose. This conversion was confirmed by

Table 2 Influence of co-catalysts on the solid residue mass and HMF and furfural yields ${ }^{a}$

\begin{tabular}{|c|c|c|c|c|c|c|}
\hline Entry & Co-catalyst & Co-catalyst mass/g & Time/min & $\mathrm{HMF}_{\text {yield }}^{b} / \%$ & Furfural yield ${ }^{c} / \%$ & Solid residues ${ }^{d} / g$ \\
\hline 1 & $\mathrm{NaH}_{2} \mathrm{PO}_{4}$ & 0.02 & 60 & 44 & 88 & 0.459 \\
\hline 2 & $\mathrm{NaHSO}_{4}$ & 0.01 & 60 & 22 & 66 & 0.605 \\
\hline 3 & $\mathrm{NaHSO}_{4}$ & 0.02 & 60 & 33 & 74 & 0.531 \\
\hline 4 & $\mathrm{NaHSO}_{3}$ & 0.02 & 60 & 37 & 84 & 0.590 \\
\hline
\end{tabular}

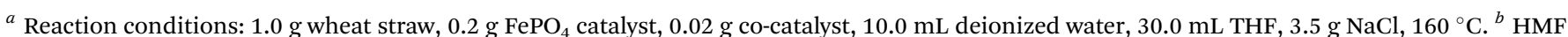

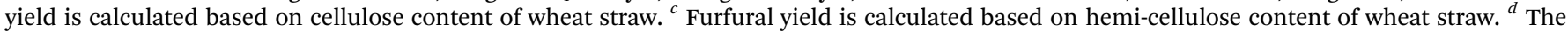
solid residue is mainly consisted of unreacted feedstock, $\mathrm{FePO}_{4}$ catalyst and side products such as humins. 


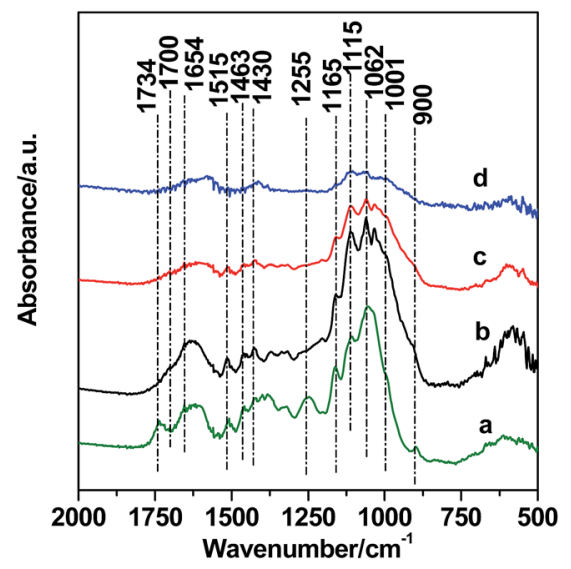

Fig. 4 IR spectra of (a) untreated wheat straw, and the solid residue obtained by the conversion of wheat straw at $160{ }^{\circ} \mathrm{C}$ for different reaction times: (b) $30 \mathrm{~min}$, (c) $60 \mathrm{~min}$, and (d) $90 \mathrm{~min}$. Reaction conditions: $1.0 \mathrm{~g}$ wheat straw, $0.2 \mathrm{~g} \mathrm{FePO}_{4}$ catalyst, $0.02 \mathrm{~g} \mathrm{NaH}_{2} \mathrm{PO}_{4}$, $10.0 \mathrm{~mL}$ deionized water, $30.0 \mathrm{~mL}$ THF, $3.5 \mathrm{~g} \mathrm{NaCl}$.

comparing the solid residue masses after reaction times of $30 \mathrm{~min}$ and $90 \mathrm{~min}(0.609 \mathrm{~g}$ and $0.451 \mathrm{~g}$, respectively; Table 1 , entries 8 and 9).

\subsection{The pyrolysis of the solid residue}

As mentioned above, the solid residues contained some cellulose with high crystallinity and insoluble lignin, which can be used as pyrolysis materials. Table 3 summarizes the pyrolysis GC-MS results of the liquid composition obtained from the fast pyrolysis of the solid residues. As can be observed, the dominant products of the bio-oils are acetic acid, furan compounds, and aromatic compounds. The acetic acid and furan compounds were produced from microcrystalline cellulose since the hemicelluloses had been completely hydrolyzed (Fig. 4). In addition, the content of acetic acid dropped from $9.76 \%$ for wheat straw to $1.97 \%$ for the solid residues obtained from the reaction at $160{ }^{\circ} \mathrm{C}$ for $90 \mathrm{~min}$ (Table 1, entry 9). This drop occurred because all of the hemicellulose and most of the cellulose had been hydrolyzed in the first step. Interestingly, 2,5-dimethylfuran and 2-methylfuran were detected in the biooils; however, the two compounds were not formed in the biooils derived from the non-catalytic pyrolysis of wheat straw. The is due to the ability of $\mathrm{FePO}_{4}$ to catalyze the conversion cellulose to 2,5-dimethylfuran and 2-methylfuran, which can be produced through the hydrolysis and hydrogen transfer reactions of 5-hydroxymethylfurfural..$^{43}$ Interestingly, it was found that the levoglucosan content of bio-oil produced from the hydrolyzed wheat straw is much higher than that from the wheat straw, which is attributed to the catalytic role of $\mathrm{FePO}_{4}$ in the solid residues. Aromatic compounds such as $p$-cresol, phenol, guaiacol, and 2,6-methoxy-phenol, were generated from the pyrolysis of lignin in the solid residues. After pyrolysis, the solid products were characterized by XRD and XPS (Fig. 3S and $4 \mathrm{~S}$, ESI $\dagger$ ). The obtained solids contained $\mathrm{FePO}_{4}$ and bio-char. In addition, the obtained bio-char also contains additional elements, such as $\mathrm{P}$ and $\mathrm{Na}$, which come from the ash of wheat
Table 3 Relative peak area distribution of the main products for wheat straw or its solid residues in $\mathrm{Py}-\mathrm{GC} / \mathrm{MS}^{a}$

\begin{tabular}{llllll}
\hline & & \multicolumn{3}{l}{ Relative content (\%) } \\
\cline { 3 - 6 } Entry & Compound & $\mathrm{S} 1$ & $\mathrm{~S} 2$ & $\mathrm{~S} 3$ & $\mathrm{~S} 4$ \\
\hline & & & & & \\
1 & Acetic acid & 9.76 & 3.72 & 1.67 & 1.97 \\
2 & 2,5-Dimethylfuran & - & 1.71 & 1.09 & 1.13 \\
3 & 2-Butenoic acid, methyl ester & - & - & 2.33 & 5.70 \\
4 & 1-Hydroxy-propane & 6.39 & 3.19 & 6.39 & 2.66 \\
5 & 2-Oxo-propionic acid & 1.56 & 2.28 & 1.66 & 1.74 \\
& methyl ester & & & & \\
6 & 2-Methylfuran & - & 2.19 & 1.07 & 1.05 \\
7 & Furfural & 1.61 & 1.32 & 0.82 & 0.80 \\
8 & 1,2-Cyclopentanedione & 3.22 & 0.99 & 1.63 & 2.57 \\
9 & Phenol & 3.10 & 2.77 & 1.96 & 2.29 \\
10 & 3-Methyl-1,2- & 2.43 & 0.40 & - & 1.55 \\
& cyclopentanedione & & & & \\
11 & p-Cresol & 0.73 & 1.17 & 3.15 & 0.73 \\
12 & Guaiacol & 2.84 & 4.61 & 4.71 & 4.95 \\
13 & 5-Methylguaiacol & 2.13 & 1.11 & 3.15 & 3.13 \\
14 & 2,3-Dihydro-benzofuran & 4.36 & 4.36 & 1.52 & 1.79 \\
15 & 4-Ethyl-guaiacol & 1.16 & - & 2.42 & 2.08 \\
16 & 4-Vinylguaiacol & 5.89 & 2.36 & 3.83 & 4.07 \\
17 & 2,6-Dimethoxy-phenol & 3.08 & 4.71 & 4.17 & 4.38 \\
18 & 4-(1-Propenyl)-guaiacol & 1.24 & 1.25 & 0.85 & 0.93 \\
19 & Levoglucosan & 1.03 & 1.39 & 5.88 & 4.81
\end{tabular}

${ }^{a} \mathrm{~S} 1$ - wheat straw; S2, S3, and S4 - the solid residue obtained from the reaction of wheat straw at $160{ }^{\circ} \mathrm{C}$ for 30,60 , and $90 \mathrm{~min}$. Reaction conditions: $1.0 \mathrm{~g}$ wheat straw, $0.2 \mathrm{~g} \mathrm{FePO}_{4}$ catalyst, $0.02 \mathrm{~g} \mathrm{NaH} \mathrm{PO}_{4}$, $10.0 \mathrm{~mL}$ deionized water, $30.0 \mathrm{~mL}$ THF, $3.5 \mathrm{~g} \mathrm{NaCl}$.

straw. Hence, it is expected that the solids produced from the catalytic pyrolysis may be used for the production of phosphate fertilizers. Therefore, catalytic pyrolysis is an effective method to further convert the hydrolyzed solid residues into valuable chemicals. It should be noted that the pyrolysis experiments of solid residues only sought to explore the feasibility of producing biochar-based phosphate fertilizers; additional work to optimize this process and a composition analysis of bio-gas will need to be completed.

\section{Conclusion}

In summary, we report an innovative approach for the complete conversion of untreated wheat straw into valuable chemicals, including 5-HMF, furfural, bio-oils, and phosphate fertilizers, by a combination of hydrolysis and catalytic pyrolysis. The combination of $\mathrm{FePO}_{4}$ and $\mathrm{NaH}_{2} \mathrm{PO}_{4}$ used as co-catalyst exhibited higher selectivity towards $\mathrm{HMF}$ and furfural production than single $\mathrm{FePO}_{4}$ or $\mathrm{NaH}_{2} \mathrm{PO}_{4}$ catalyst systems, indicating that a synergistic combination of Lewis and Brønsted acid sites is critical to obtain high yields of furan compounds. An HMF yield of $44 \%$ was obtained when the reaction was carried out at $160{ }^{\circ} \mathrm{C}$ for $60 \mathrm{~min}$, while the highest yield of furfural, $92 \%$, was achieved at $150{ }^{\circ} \mathrm{C}$ for $60 \mathrm{~min}$. Excessive Brønsted or Lewis acid sites (Fe ions) are unfavorable for the production of HMF and furfural due to the formation of by-products. The solid residue obtained from the hydrolysis reaction was pyrolyzed to produce bio-oils and phosphate fertilizers. The bio-oils, which were 
produced from the rapid catalytic pyrolysis of the solid residues, contained many value-added compounds, including furan and aromatic compounds. This novel strategy provides an efficient pathway to efficiently convert all lignocellulosic materials into valuable compounds.

\section{Acknowledgements}

This work was financially supported by the National Natural Science Foundation of China (grant no. 31200445), and the Natural Science Foundation of Jiangsu province (grant no. BK2012416). This work was also financially supported by the Natural Science Foundation of Jiangsu Higher Education Institutes of China (16KJB220003), the Priority Academic Program Development of Jiangsu Higher Education Institutions (PAPD) and Top-notch Academic Programs Project of Jiangsu Higher Education Institutions (TAPP).

\section{References}

1 R.-J. van Putten, J. C. van der Waal, E. de Jong, C. B. Rasrendra, H. J. Heeres and J. G. de Vries, Chem. Rev., 2013, 113, 1499-1597.

2 M. E. Zakrzewska, E. Bogel-Lukasik and R. Bogel-Lukasik, Chem. Rev., 2010, 111, 397-417.

3 H. Huang, C. A. Denard, R. Alamillo, A. J. Crisci, Y. Miao, J. A. Dumesic, S. L. Scott and H. Zhao, ACS Catal., 2014, 4, 2165-2168.

4 Y. Roman-Leshkov, J. N. Chheda and J. A. Dumesic, Science, 2006, 312, 1933-1937.

5 Y. Roman-Leshkov and J. A. Dumesic, Top. Catal., 2009, 52, 297-303.

6 X. Chen, S. L. Chew, F. M. Kerton and N. Yan, Green Chem., 2014, 16, 2204-2212.

7 S. Siankevich, G. Savoglidis, Z. Fei, G. Laurenczy, D. T. L. Alexander, N. Yan and P. J. Dyson, J. Catal., 2014, 315, 67-74.

8 S. Siankevich, Z. Fei, R. Scopelliti, G. Laurenczy, S. Katsyuba, N. Yan and P. J. Dyson, ChemSusChem, 2014, 7, 1647-1654.

9 J. Q. Bond, A. A. Upadhye, H. Olcay, G. A. Tompsett, J. Jae, R. Xing, D. M. Alonso, D. Wang, T. Zhang, R. Kumar, A. Foster, S. M. Sen, C. T. Maravelias, R. Malina, S. R. H. Barrett, R. Lobo, C. E. Wyman, J. A. Dumesic and G. W. Huber, Energy Environ. Sci., 2014, 7, 1500-1523.

10 M. A. Kabel, G. Bos, J. Zeevalking, A. G. J. Voragen and H. A. Schols, Bioresour. Technol., 2007, 98, 2034-2042.

11 O. Yemis and G. Mazza, Bioresour. Technol., 2012, 109, 215223.

12 R. J. H. Grisel, J. C. van der Waal, E. de Jong and W. J. J. Huijgen, Catal. Today, 2014, 223, 3-10.

13 J. Zhuang, Y. Liu, Z. Wu, Y. Sun and L. Lin, BioResources, 2009, 4, 674-686.

14 Z. Wu, H. Hao, Z. Y. Tu, Z. Hu, F. Wei, Y. Liu, Y. Zhou, Y. Wang, G. Xie, C. Gao, X. Cai, L. Peng and L. Wang, Biomass Bioenergy, 2014, 70, 347-355.

15 H. Li, Q. Dai, J. Ren, L. Jian, F. Peng, R. Sun and G. Liu, Carbohydr. Polym., 2016, 136, 203-209.
16 A. Deng, J. Ren, H. Li, F. Peng and R. Sun, RSC Adv., 2015, 5, 60264-60272.

17 S. Sun, S. Sun, X. Cao and R. Sun, Bioresour. Technol., 2016, 199, 49-58.

18 G. Yi, S. P. Teong and Y. Zhang, Green Chem., 2016, 18, 979-983.

19 G. Yi, S. P. Teong, X. Li and Y. Zhang, ChemSusChem, 2014, 7, 2131-2135.

20 S. Siankevich, Z. Fei, R. Scopelliti, P. G. Jessop, J. Zhang, N. Yan and P. J. Dyson, ChemSusChem, 2016, 9, 2089-2096.

21 Z. Zhang, J. Zhen, B. Liu, K. Lv and K. Deng, Green Chem., 2015, 17, 1308-1317.

22 S. Wang, Z. Zhang, B. Liu and J. Li, Ind. Eng. Chem. Res., 2014, 53, 5820-5827.

23 R.-J. van Putten, J. N. M. Soetedjo, E. A. Pidko, J. C. van der Waal, E. J. M. Hensen, E. de Jong and H. J. Heeres, ChemSusChem, 2013, 6, 1681-1687.

24 Y. Zhang, V. Degirmenci, C. Li and E. J. M. Hensen, ChemSusChem, 2011, 4, 59-64.

25 N. A. S. Ramli and N. A. S. Amin, Appl. Catal., B, 2015, 163, 487-498.

26 J. Y. G. Chan and Y. Zhang, ChemSusChem, 2009, 2, 731-734. 27 S. Xu, X. Yan, Q. Bu and H. Xia, RSC Adv., 2016, 6, 8048-8052.

28 L. Yang, X. Yan, S. Xu, H. Chen, H. Xia and S. Zuo, RSC Adv., 2015, 5, 19900-19906.

29 H. Xia, S. Xu, X. Yan and S. Zuo, Fuel Process. Technol., 2016, 152, 140-146.

30 L. Hu, X. Tang, J. Xu, Z. Wu, L. Lin and S. Liu, Ind. Eng. Chem. Res., 2014, 53, 3056-3064.

31 B. Saha, C. M. Bohn and M. M. Abu-Omar, ChemSusChem, 2014, 7, 3095-3101.

32 B. Liu, Y. Ren and Z. Zhang, Green Chem., 2015, 17, 1610-1617.

33 Y. Shen, Y. Xu, J. Sun, B. Wang, F. Xu and R. Sun, Catal. Commun., 2014, 50, 17-20.

34 D. Shen, J. Zhao, R. Xiao and S. Gu, J. Anal. Appl. Pyrolysis, 2015, 111, 47-54.

35 P. D. Muley, C. Henkel, K. K. Abdollahi, C. Marculescu and D. Boldor, Energy Convers. Manage., 2016, 117, 273-280.

36 A. Sluiter, B. Hames, R. Ruiz, C. Scarlata, J. Sluiter, D. Templeton and D. Crocker, Determination of Structural Carbohydrates and Lignin in Biomass. Laboratory Analytical Procedure, National Renewable Energy Laboratory (NREL), Golden, CO, 2012.

37 J. B. Binder and R. T. Raines, J. Am. Chem. Soc., 2009, 131, 1979-1985.

38 C. M. Cai, N. Nagane, R. Kumar and C. E. Wyman, Green Chem., 2014, 16, 3819-3829.

39 N. Meine, R. Rinaldi and F. Schueth, ChemSusChem, 2012, 5, 1449-1454.

40 R. Weingarten, A. Rodriguez-Beuerman, F. Cao, J. S. Luterbacher, D. M. Alonso, J. A. Dumesic and G. W. Huber, ChemCatChem, 2014, 6, 2229-2234.

41 S. D. Zhu, Y. X. Wu, Q. M. Chen, Z. N. Yu, C. W. Wang, S. W. Jin, Y. G. Ding and G. Wu, Green Chem., 2006, 8, 325-327.

42 K. L. Iroba, L. G. Tabil, S. Sokhansanj and T. Dumonceaux, Biomass Bioenergy, 2014, 66, 286-300.

43 H. Xia, X. Yan, S. Xu, L. Yang, Y. Ge, J. Wang and S. Zuo, J. Chem., 2015, 749875. 